\title{
What are the core ideas behind the Precautionary Principle?
}

\section{Erik Persson \\ Umeå University, Department of Historical, Philosophical and Religious Studies, 90187 Umeå, Sweden}

\section{H I G H L I G H T S}

- Identification of the core ideas of the Precautionary Principle.

- Systematically underestimated values justify extra precaution.

- Threats of irreversible, irreplaceable, severe effects justifies extra precaution.

- Extra precaution is justified when timing is at least as important as being right.

- Extra precaution is justified when false negatives are worse than false positives.

\section{A R T I C L E I N F O}

\section{Article history:}

Received 15 January 2016

Received in revised form 6 March 2016

Accepted 7 March 2016

Available online 18 March 2016

Editor: D. Barcelo

\section{Keywords:}

Irreversibility

Irreplaceable values

Epistemic values

Environmental values

Rio declaration

Precaution

\section{G R A P H I C A L A B S T R A C T}

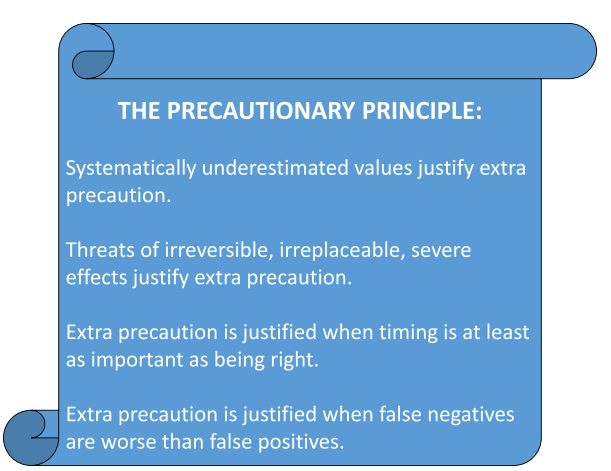

\section{A B S T R A C T}

The Precautionary Principle is both celebrated and criticized. It has become an important principle for decision making, but it is also subject to criticism. One problem that is often pointed out with the principle is that is not clear what it actually says and how to use it. I have taken on this problem by performing an analysis of some of the most influential formulations of the principle in an attempt to identify the core ideas behind it, with the purpose of producing a formulation of the principle that is clear and practically applicable.

It was found that what is called the Precautionary Principle is not a principle that tells us what do to achieve extra precaution or how to handle situations when extra precaution is called for. Instead, it was found to be a list of circumstances that each justify extra precaution. An analysis of some of the most common and influential formulations of the Precautionary Principle identified four such circumstances: (1) When we deal with important values that tend to be systematically downplayed by traditional decision methods - such as human health and the environment. (2) When we suspect that the decision might lead to irreversible and severe consequences and the values at stake are also irreplaceable, (3) When timing is at least as important as being right. (4) When it is more important to avoid false negatives than false positives.

This interpretation of the Precautionary Principle does not say anything about what kind of actions to take when extra precaution is called for, but it does provide a clear and practically useful list of circumstances that call for extra precaution and that is not subject to the most common objections to the Precautionary Principle.

(c) 2016 Elsevier B.V. All rights reserved.

\section{Introduction}

The Precautionary Principle has become an important tool for decision making. This principle is recommended or even prescribed by many official sources. These include international declarations 
and treaties such as the Rio declaration, Agenda 21 and the constitution of the European Union, and also national as well as regional and local legislation in many countries (Ambrus, 2012; Beltrán, 2001; Commonwealth Consolidated Acts, 1999; Cooney and Dickson, 2005; Gignon et al., 2013; Gollier and Treich, 2003; Grandjean, 2004; Grandjean et al., 2004; Herremoës et al., 2001; Lin, 2001; Melin, 2001; O'Riordan and Jordan, 1995; Osimani, 2013; Purnhagen, 2014; Rio Declaration, 1992; Raffensperger and Tickner, 1999; Sandin, 2004a, 2004b; Steel, 2015; Turner and Hartzell, 2004; Walsh, 2004; Whiteside, 2006). It has, however also been criticized from a variety of sources and it remains controversial (Cooney and Dickson, 2005; Gignon et al., 2013; Gollier and Treich, 2003; Grandjean, 2004; Grandjean et al., 2004; Hermele, 1995; Munthe, 1997; O'Riordan and Jordan, 1995; Osimani, 2013; Sandin, 1999, 2004b; Sandin et al., 2002; Steel, 2015; Turner and Hartzell, 2004; Whiteside, 2006). The problem that is most commonly raised is that the principle is unclear (Ambrus, 2012; Gollier and Treich, 2003; Graham, 2001a, 2001b; Manson, 2002; Mayer et al., 2002; Osimani, 2013; O'Riordan and Jordan, 1995; Purnhagen, 2014; Sandin, 1999; Sandin, 2004a; Sandin et al., 2002; Steel, 2015; Turner and Hartzell, 2004; Whiteside, 2006). In order to deal with that problem, I will here present a more "tidy" and transparent version of the Precautionary Principle with defined boundaries for its applicability. This version of the principle was derived from an analysis of the most common formulations of the Precautionary Principle, with the aim of identifying the most basic ideas behind the principle.

The analysis revealed that the basic ideas behind the Precautionary Principle contrary to popular belief, has nothing to do with where to place the onus of proof, how certain we need to be that a new invention is safe before we give green light to use, or how to prioritize between different risks. Instead, the basic ideas behind the Precautionary Principle was shown to deal exclusively with which circumstances that justify extra precaution beyond what would be called for by other decision procedures. I therefore suggest that the Precautionary Principle should be interpreted as a list of criteria for when we need extra precaution, not as a principle telling us what to do when we think (for some reason) that we need extra precaution. It tells us, in other words, when we need extra safety and why, not what to do in these situations. This does not mean that the Precautionary Principle is useless as a decision principle. Pinpointing in which situations we need extra safety, and why this is justified is extremely important. Although the formulation presented here is more limited, it is also clearer and more easy to use, which makes it more, not less, useful in practice than previous formulations.

\section{What does the Precautionary Principle really tell us?}

There are many different formulations of the Precautionary Principle. The most commonly quoted formulation is from the Rio Declaration (Referred to among others by Ambrus, 2012; Cooney, 2005; Gollier and Treich, 2003; Grandjean, 2004; Lin, 2001; Manson, 2002; Melin, 2001; Osimani, 2013; Sandin, 1999, 2004a, 2006; Sandin et al., 2002; Stijkel and Reijnders, 1999; Walsh, 2004; Whiteside, 2006):

Where there are threats of serious or irreversible damage, lack of full scientific certainty shall not be used as a reason for postponing cost-effective measures to prevent environmental degradation.

[Rio Declaration (1992)]

The Rio declaration in general leaves much room for interpretation, and the Precautionary Principle is no exception. There is a large flora of interpretations, and there is still no real consensus (Cooney and Dickson, 2005; Sandin, 1999, 2004a). The Rio formulation has also been criticized for being too weak, and for not really telling us what to do, but only what not to do (i.e. not to use lack of scientific certainty as an excuse for not acting) (Sandin, 2006). It is true that the Rio formulation does not actually tell us what to do but it does provide something else. It points out two situations that differ from "normal" decision situations and therefore need to be treated differently. The situations that are pointed out are situations where there is a serious threat and situations where there is a risk for irreversible damage. What constitutes a serious threat is still unclear, however.

There are other competing formulations of the Precautionary Principle and they too are intensely debated (Cooney and Dickson, 2005). One formulation that is often referred to is the so-called Wingspread formulation (Grandjean, 2004; Osimani, 2013; Sandin, 1999, 2004b, 2006; Turner and Hartzell, 2004; Whiteside, 2006). It was formulated six years after the Rio formulation at a conference with a number of scientists, activists, etc. from different countries (though mostly from North America). It states the principle as follows:

When an activity raises threats of harm to human health or the environment, precautionary measures should be taken even if some cause and effect relationships are not fully established scientifically.

[Wingspread Conference (1998)]

Contrary to the Rio formulation, the Wingspread formulation is stated as a positive prescription. In practice this does not make much of a difference, however, since it does not tell us what kinds of measures we should take, other than that they should be precautionary. Like the Rio formulation, it concentrates on telling us which situations call for extra precaution. Here, it is somewhat more specific than the Rio formulation, however. It also includes human health among the relevant considerations. This was not mentioned by the Rio formulation.

Also other formulations seem to point in about the same direction even though they differ in the details (Gollier and Treich, 2003). Grandjean et al. (2004) interpret the Precautionary Principle as:

... a tool for avoiding possible future harm associated with suspected, but not conclusive, environmental risks.

Just like the Rio formulation and the Wingspread formulation, Grandjean et al. abstain from providing any advice on what to actually do to avoid possible future harm, not to mention a tool for doing so. Just like the two previously mentioned formulations, it instead provides us with criteria for when to take such measures. In this case, the criteria is that we stand before suspected but not conclusive future harm that is associated with environmental risk. Exactly what degree of suspicion is called for is not specified, however.

Per Sandin defines the core idea of the Precautionary Principle as follows:

... on some occasions, measures against a possible hazard should be taken even if the available evidence does not suffice to treat the existence of that hazard as a scientifically established fact (Sandin, 2004a, similarly stated in Sandin et al., 2002 and Sandin, 2004b).

Just like the others, Sandin does not specify which measures to take but he does give us a clue for under which conditions such measures are called for, namely when we face a possible hazard that is not scientifically established.

Whiteside presents an interpretation that is a bit more elaborate than the others, but the basic ideas seem to be the same:

... the precautionary idea in risk regulation is at work whenever authorities take early preventive measures to forestall a potential, irreversible danger, even though causal links in the chain leading to that danger have not yet been firmly scientifically established.

[Whiteside (2006)]

Again, nothing is said about which measures to take but it is indicated in which types of situations they are motivated. In this 
case, preventive measures are called for when we face a potential but not scientifically established danger that is also irreversible.

Timothy O'Riordan's and Andrew Jordan's interpretation reads:

At the core of the Precautionary Principle is the intuitively simple idea that decision makers should act in advance of scientific certainty to protect the environment (and with it the well-being interests of future generations) from incurring harm.

[O'Riordan and Jordan (1995)]

This version is like the others a listing of situations in which extra precaution is called for. It points out threat to the environment and future generations and just as was the case with several of the other interpretations it stresses lack of scientific certainty. Like all the other interpretations it also abstains from pointing out what kind of measures that should be taken in these situations.

These are some examples of how different authors have tried to identify the core of the Precautionary Principle. The formulations differ, but they also seem to have some basic ideas in common. In the coming sections I will try to identify these ideas and determine if they can justify that we at some occasions take precautionary measures that for instance go beyond what a standard cost-benefit analysis would recommend.

One noticeable feature of all these formulations is that they all specify under what circumstances precautionary methods should be taken, but they do not specify which measures should be taken. Based on these formulations, I therefore suggest that the Precautionary Principle is actually a list of circumstances that are supposed to justify extra precaution compared to what is typically recommended by standard decision methods such as cost-benefit analyses. It does not come through as a complete decision model that recommends particular measures. This is important to remember both when using the principle and when trying to criticize it.

\section{The value of human health and the environment}

It is sometimes claimed that values like human health and the environment tend to be downplayed in traditional decision procedures (See e.g. Turner and Hartzell, 2004; Wingspread Conference, 1998). Threats against human health or the environment are also explicitly stated in many formulations of the Precautionary Principle (Cooney and Dickson, 2005; Gollier and Treich, 2003; O'Riordan and Jordan, 1995; Sandin, 1999, 2006; Turner and Hartzell, 2004; Wandall, 2004).

This indicates that one of the ideas behind the principle is that human health and the environment need to be better protected than has been the case in traditional decision procedures and that a precautionary approach is needed to achieve that.

In cases were human health and the environment competes with other values, some kind of trade-off must be done. Maybe one motive behind the Precautionary Principle is to be found in the way the tradeoff between things such as human health and the environment on one hand and other values on the other, is normally done. It seems that the value people place on the former is ascending, and it might therefore be that when economists and decision makers make comparisons between them and other values, human health and the environment are assigned a value that is too low. Some authors believe that problems in connection with the trade-off between different values are a major motive behind the Precautionary Principle (O'Riordan and Jordan, 1995).

The question that immediately arises is whether this change in value cannot be dealt with in a simpler way by just assigning a higher value to the environment and human health in ordinary cost-benefit analyses. The answer is that this may not help since the problem may be inherent in the model. The entire decision procedure seems to be biased to the advantage of values that can be traded on the market and to the disadvantage of values that cannot, like human health and the environment.

In order to be fitted into existing decision models, values that are not traded on the market have to be translated into monetary value in some more or less artificial way (Chee, 2004; Costanza et al., 1997; Herendeen, 1998; Naidoo and Ricketts, 2006; Sukhdev, 2010). How this should be done is far from clear, however. Values like the environment and human health are notoriously difficult to express in monetary terms. Some even claim that it is genuinely impossible. Even so, it is frequently done, though the usefulness of the results is debated (Attfield, 1998; Barbier, 1994; Costanza and Folke, 1997; Chan et al., 2012; Chee, 2004; Diamond and Hausman, 1994; Garrod and Willis, 1999; Ludwig, 2000; Neurath, 1973; O'Neill, 2002; Owen et al., 2009; Payne et al., 1992; Plottu and Plottu, 2007; Randall, 1988; Raymond et al., 2013; Samples and Hollyer, 1990; Steel, 2015; Söderbaum, 1987, 1994; Wilson and Howarth, 2002). If it is not possible to correctly account for the value of human health and the environment in monetary terms, then cost-benefit analyses will be systematically misleading in trade-offs were these values are involved. This uncertainty whether the value of things like human health and the environment can be correctly accounted for in monetary terms seems like a good example of a special situation that clearly justifies extra precaution.

An example of such a situation could be when a pipeline for oil is drawn across a sensitive nature area. In this case, the Precautionary Principle would tell us a. that more precaution is called for than when the pipeline is drawn in an area where a leak would cause less havoc to human health or the environment, and b. that more precaution is justified than what would be recommended by a cost-benefit analysis that compares the cost of precaution with the negative value (or the expected negative value) of a leak, where the negative value is based on a mix of economic value (the cost of fixing the leak, cleaning up after the leak, etc.) and a contingent valuation of the nature in the area.

The reason for talking about values 'like' or 'such as' human health and the environment is that on one hand, these are the only values that are specifically mentioned by the most influential formulations of the Precautionary Principle, on the other hand, human health and the environment are not the only values that are not traded on the market. In order to be true to the purpose of this investigation and formulate the basic ideas of the Precautionary Principle based on an analysis of the standard formulations of the principle, I will suffice with including those values explicitly mentioned in these formulations (that is, the environment and human health), but it might be that future improvements of the principle should include also other values in the same situation.

It might be objected that an urge to take extra precaution in situations where human health or the environment is threatened can lead to contradictions. For this formulation of the Precautionary Principle, this is not the case, however. It is true that in certain situations it can urge us to take extra precaution against a potential threat to the environment, where the threat consists of an action that is taken to protect human health. Consider for example the use of a pesticide that is used to fight a parasite that causes large amounts of suffering and deaths among humans. Imagine that the pesticide also causes havoc in the ecosystem. In this case we are dealing with two competing values that both fulfil the criteria for special concern. What does the Precautionary Principle tell us to do in this situation? Remember that the Precautionary Principle is not a tool for making trade-offs and it does not tell us that certain values should always be promoted or protected over other values, or that some things are more valuable than others. It does therefore not tell us to minimize the risk for either human health or the environment on the other's expense. The Precautionary Principle can thus not tell us whether the negative value of the human suffering and death from the parasite that occurs today is higher (and in that case how much higher) or lower (and in that case, how much lower) than the value of the undamaged ecosystem. What it tells us, is that no matter how you make the trade-off, you have to take more precaution to 
protect both (given the trade-off) than a cost-benefit analysis would. Exactly how to do that involved too many variables (what technologies are available, what is the income level of the population, what species is the ecosystem made up of, what is the typical wind direction in the area, etc.) to bake into a general principle. It might be that we need to choose an alternative way of protecting health of the human population, it might be that we should use the pesticide but only during certain times of the year or outside of certain areas, for instance. The point is that we, in a case like this, need to spend more (money, time, or other resources) on precaution for both the human health and the environment than would be justified by a cost-benefit analysis.

\section{Irreversibility}

Irreversibility is mentioned in several formulations of the Precautionary Principle, including the Rio formulation (see e.g. Attfield, 1998; Herremoës et al., 2001; O'Riordan and Jordan, 1995; Rio Declaration, 1992; Rolston, 1988; Whiteside, 2006; World Commission on Environment and Development, 1987). Can irreversibility be such a big problem that it grants extra precaution beyond what would be prescribed by for instance a cost-benefit analysis?

A complicating factor when it comes to assessing the role of irreversibility in the Precautionary Principle is that none of the standard formulations specify exactly what they mean by 'irreversibility'. A process can be more or less difficult to reverse. How difficult does it have to be before we call it 'irreversible' and give it a special status? Is it enough that it is too difficult or expensive for the decision makers to be willing to take the risk? Does it have to be impossible with existing technology, or with any technology that is plausible within a reasonable future (and what does that mean), or does it have to be impossible per definition? (An example of the latter would be an extinct species defined according to a species concept based on historical lineages. If the lineage is cut off, the species is extinct forever, even if it would be possible to recreate an exact copy of a member of the species.)

I will not here take a stand on exactly where to draw the line (see Manson, 2007 for a more in depth discussion). Though in order to construct a practically useful principle, I suggest that 'irreversible' when used as a part of the Precautionary Principle, is defined in relation to the value at stake and in terms of what is practically possible in the situation in question.

Manson (2002) mentions a test case that the reference to irreversibility in the Precautionary Principle should be able to handle: "Consider a decision maker confronted with the proposal to dam a river. He or she knows that the dam will result in the death of all of the native trout, but also knows that in the future the dam can be removed and the river restocked with non-native trout." He asks, is the effect irreversible or not?

In this case, it all depends on which is the value at stake, which in turn is a question that has to answered by the stakeholders (it cannot be answered by science or by any decision principle). If the value at stake is the presence of native trout (or possibly the future existence of the native trout if this is its only habitat), then the answer given the assumptions of Manson's example, is that the process is irreversible. If the value at stake is the presence of some subspecies of trout, or the value assigned to the fish in question is simply nutritional or economic, it might not be irreversible. When Per Sandin discusses irreversibility as an aspect of precaution, he describes it as one of three aspects of 'threat' that are relevant for our understanding of the Precautionary Principle. The three aspects are: Severity, irreversibility and preventability (Sandin, 1999). If a threat is not preventable (that is, if it is inevitable), it is meaningless to take precautionary measures (it would not even be possible to identify any measures as being precautionary). Preventability is therefore a necessary prerequisite for any talk about precaution or risk management in general. That severity is relevant seems intuitively plausible as well. The more severe an outcome is, the more important it must be to take precautionary measures against it. It is also intuitively plausible that a certain degree of severity is a necessary prerequisite for invoking precautionary measures. An event that is irreversible but not negative at all hardly calls for precaution, and an event that is only slightly negative but can quite easily be counterbalanced by the positive effects that you get from the process that causes the irreversible change, should reasonably be treated as one value among others and be dealt with in a normal cost-benefit analysis. Sandin illustrates the importance of severity by an example of a boulder that is crushed in order to get gravel (Sandin, 1999). This is clearly an irreversible act, but it can hardly be described as severe.

In fact, irreversibility might even on some occasions be a good thing. If we manage to get permanently rid of some great evil, it is surely something positive and the irreversibility of the outcome makes it more, not less positive.

So far it seems that irreversibility cannot be a sufficient reason for invoking extra precaution. It has to occur in combination with some degree of severity (in addition to the obvious criteria of preventability).

On the other hand, when we deal with a possible effect that is highly negative (severe), and it turns out to be irreversible as well, the irreversibility may well be a factor that enhances the problem to such a degree that it gives the problem a special status that compels us to take extra precaution.

One might want to argue that since it is not specified which degree of severity is needed to evoke the Precautionary Principle, it is not very useful. I would like to argue, on the other hand, that a principle that pretends to be able to settle that question should be viewed with great suspicion since it contains a value judgement that should be reserved for the stakeholders, and not pre-decided by someone else and hidden in a general principle, and thereby pushing one person's valuation onto everyone who uses the principle. By this I do not mean that science can be totally value free, or that values cannot be subject to objective analysis. My point is instead that everyone who is concerned by a decision must have a say in that decision, and that the question of how valuable or how severe something is as well as the question of deciding how valuable or severe something has to be to grant extra precaution are exactly the right places for this.

We still have to ask ourselves, however, why this combination of irreversibility and severity cannot be handled by for instance determining how much more negative a negative effect becomes if it is also irreversible, and then add this additional value to the negative value of the effect as such and then it with a common cost-benefit analysis. The irreversibility issue goes deeper than this, however. Per Sandin compares the Precautionary Principle with a decision principle used by insurance companies. When making business decisions, the insurance companies try to "...maximize expected monetary value, but only if bankruptcy is not one of the possible outcomes." (Sandin, 2004a). This seems like a sensible decision principle: Use cost-benefit analyses but make no decisions that if they fail will result in bankruptcy.

The question is: What makes bankruptcy so special? Irreversibility probably plays a substantial part: It is bad if we lose money on a deal, but we can come back and make money on another deal. It is also a pity if we stay out of a deal that would have rendered us a great profit, but we can, in general, make money on another deal (even though we have lost some opportunity value by opting out of this deal). If we go bankrupt on the other hand, it is over. It is true that all business opportunities are irreversible in a weak sense, meaning that this particular opportunity will never come back. In fact, in a very weak sense, everything that happens is irreversible because of (what seems to be) the fact that time is a one-way street (often defined in terms of the law of entropy as time moving in the direction in which entropy increases) (Manson, 2002, 2007). A bankruptcy seems to be irreversible in a stronger sense, however, since it means not just that this particular event cannot be undone (the very weak sense), or even that a particular opportunity will not come back (the weak sense), but that the company can never do business again at all. From the point of view of the company (if we pretend for a moment that there is such a thing as the point of view of a company), it makes sense to consider this a special case, though 
from the point of view of the owners, individual employees or other members of the society this is not necessarily the case. The employees can get new jobs and the owner of the company can start a new company even in the same branch. This means that from the point of view of the society, the bankruptcy of a company might not grant any extra precautionary measures. Things would be different, however, if this company was also, for some reason, irreplaceable. Maybe it would be impossible for the country to replace the lost jobs, or maybe it would make the country dependant on foreign import of some strategic commodity. It is therefore the combination of being irreversible and irreplaceable in relation to some important end value, such as important ecosystem services, or things that have value as ends in themselves, that makes it a special case. Ordinary cost-benefit analyses based on expected value may well be the most rational decision method when we talk about "ordinary" events such as recurring economic deals. In these cases, expected value is probably a good account of the longterm gain or loss, and extremes that happen quite seldom are, in general, outweighed in the long term by the sum of the smaller but more common events. On the other hand, if we talk about something that cannot be allowed to happen even once, it seems rational to adopt an alternative strategy for decision-making.

The conclusion is that irreversibility is not on its own sufficient for extra precautionary measures to be justified. However, when the outcome is in the form of a severe loss that is not just irreversible but also irreplaceable, this puts it in a special category that calls for extra precaution.

Irreplaceability is not mentioned in any of the standard formulations of the Precautionary Principle but since it is necessary to make sense of the focus on irreversibility. I conclude that it is justified to include it.

\section{The cost of being late}

All the formulations of the Precautionary Principle quoted above talk about the importance of not waiting for conclusive evidence before taking measures. This may look at first sight as an attack on the rules of science. This is not the case, however. This idea has to do with how to use science in rational decision making, not with how science should be done as such.

This idea can be divided into two different criteria for when we need extra precaution. One that has to do with timing and that tells us that when we are in possession of scientific evidence that indicates a risk, then we should not wait until we have a complete understanding of the situation before we act. The other tells us that even though false positives are typically worse for the epistemic values that rule science than false negatives, this is not always the case for the society in general. This in turn means that in some cases we need to use the scientific results differently when we are about to make decision about nonepistemic values compared to if we are to decide whether to include a result in the scientific corpus. I will discuss these two ideas in this and the next section. I will start with the time aspect.

Many formulations of the Precautionary Principle mention the importance of considering the value of what we might lose if we do not take measures. This looks reasonable but is not sufficient to form a justification for not waiting for a more complete scientific understanding. That it is important to consider the values at stake can just as well be an argument for taking the extra time needed to make sure that an intervention does not worsen the situation. In order to get to the conclusion that we should not wait, we need an additional argument stressing the importance of timing when it comes to securing the values in question.

Traditionally an economically profitable substance or process can only be banned or regulated on behalf of other values like human health if we have very strong evidence of the risks posed to these values by the substance or process in question. Gathering the necessary evidence may take time, however, and much can happen during this time (Herremoës et al., 2001; McGarvin, 2001; Sandin, 1999). The situation can grow much worse and irreversible damage may occur (Osimani, 2013; Whiteside, 2006). In recent history, both people and the environment have often suffered (and in many cases still suffer) unnecessary harm because the decision makers have waited for more conclusive evidence before dealing with a problem, and there is reason to believe that this problem is much more common than the opposite problem of regulating too fast (Steel, 2015). The European Environment Agency (EEA) report on the Precautionary Principle Late lessons from early warnings (Herremoës et al., 2001) describes several such cases in detail. The content as well as the title of the report states very clearly that the editors and authors consider time loss to be a very important motivation for the Precautionary Principle (Herremoës et al., 2001). Benzene, asbestos, and lead additives in petrol are some well-known examples (Beltrán, 2001; Gee and Greenberg, 2001; Grandjean et al., 2004; Infante, 2001), If we had not waited so long for conclusive proof that these chemicals are harmful, we could have banned them earlier and avoided some of their long-term effects (For more examples, see Cooney, 2005; Grandjean et al., 2004; Herremoës et al., 2001; Ibarreta and Swan, 2001; Koppe and Keys, 2001; von Krauss and Herremoës, 2001; Lambert, 2001; Steel, 2015).

The time factor is especially important when dealing with complex things like ecosystems or the human body. The effects often do not show until the substance or process has been in use for a while (Farman, 2001; Gee and Greenberg, 2001; Gollier and Treich, 2003; Ibarreta and Swan, 2001; von Krauss and Herremoës, 2001; Osimani, 2013; Rolston, 1988). This means that we will not have conclusive evidence that a substance is dangerous until it is already in the system (maybe in large quantities) and we may have to live with the problem for a long time. When we deal with non-linear relations and complex systems such as ecosystems and the human body, it is also very difficult to establish a clear cause-effect relationship and we may have to wait even longer than normal for conclusive evidence (Whiteside, 2006).

The idea that we under certain circumstances should not wait for conclusive evidence before taking action might seem irrational, but is in fact a very rational decision rule. All decision-makers worthy of the epithet, from stock traders to military commanders, know that even though it is important to have accurate information, it is also important to act in time. If we are too late, perfect information is to no avail. We must therefore conclude that taking action before we have conclusive evidence in situations when timing is of the essence, is not only acceptable, but morally and rationally required.

Maybe the tendency to give an unreasonably high priority to accurateness over acting in time, has been uncritically adopted by society from the realm of science, where knowledge and understanding as such are the ultimate goals. Decision makers need information, and the best way of getting reliable information is to turn to those who have the formation of knowledge as their ultimate goal, that is, to science. However, since the goals of society in general are not exactly the same as the goal of science, we need a transformation rule. I believe it is very important that this is not done by changing the rules or the aims of science. Instead, we need to foster an understanding among both scientists and decision makers that the aims are different and that it is therefore perfectly rational to have different criteria for when to add a statement to our scientific worldview and for when to act to save an important value, and that abstaining from acting to save an important value because the evidence is not strong enough to change our scientific worldview is not sound science, it is bad decision making.

What we also have to remember, is that the idea here is not to ignore knowledge already produced by science. Neither is it that we should act without any knowledge at all. The idea is rather that we need to find a balance between certainty and timing. How to find this balance in each particular situation is a delicate problem that will not be solved here. The basic idea that the different goals of science and society imply different demands on where to find this balance, is none the less important to acknowledge and to apply in decision making to the best of one's ability. 
One question that remains to be answered is when it is more important to be in time than to be exactly right. The standard formulations of the Precautionary Principle that form the basis for this investigation do not specify that. This can be seen as a problem since it might make the principle less useful for deciding whether a certain situation is a situation where extra precaution is called for or not. This problem cannot be solved by analysing the standard formulations, but once the core ideas have been identified, it will be possible to continue to build on them to make them more useful. Another way of looking at the fact that it is not specified exactly when it is more important to be in time than to be exactly right is that it is a reflection of the real world. How important something is, is ultimately a question of values and needs to be negotiated by the stakeholders involved in each particular case, and not pre-determined by a general principle.

\section{False positives versus false negatives}

Scientists do not like to be wrong. In the world of science, making a claim that turns out to be wrong is, in general, worse than abstaining from making a claim that later turns out to be true. This means that scientists tend to be biased to err in favour of false negatives over false positives (Gee and Greenberg, 2001; Grandjean, 2004; Herremoës et al., 2001; Wandall, 2004).

Birgitte Wandall calls the bias towards false negatives the "conservative burden of proof", since it confers the burden of proof on those who make a positive claim (Wandall, 2004). She also points out that the reason for this tendency is probably that one of the main values guiding science (epistemic values) is to keep the scientific corpus (the body of statements accepted by science) as free as possible from false statements (Wandall, 2004). This is the scientific community's own version of "erring on the side of caution", and it is doubtlessly a good reason to trust science: If something is claimed by the scientific community to be true, it probably is true. This also means, however, that if the scientific community does not want to exclaim something as true, it does not necessarily mean that it is false. To believe that it does seems to be an all too common mistake that in some situations can cause a good deal of harm (Whiteside, 2006). It is, after all, not obvious that the goal of avoiding false positives is always a superordinate goal in society at large. In many cases where other values are at stake, false negatives can have at least as severe effects as false positives. The effects of not regulating or banning something that is dangerous can be at least as bad as the effects of regulating or banning something that is harmless. If we accept the idea that human health and the environment (and possibly also other values like them) need to be assigned a higher value than has traditionally been the case, it is probably in many cases more important to avoid false negatives than to avoid false positives when these values are at stake (Wandall, 2004). We therefore have a case that is parallel to the idea discussed above regarding the value of acting in time. The conclusion must also be the same: We need a decision rule that can compensate for the difference in goals between science and practical decision making (for a discussion of the goals of science, see Wandall, 2004). The Precautionary Principle seems to be precisely cut out for that job. The cost of false negatives for a host of values, including human health and the environment seem, just like the cost connected with losing time, to be a strong argument in favour of precaution. Just as it is sometimes more important to act in time than being exactly right, it is sometimes more important to avoid false negatives than to avoid false positives - depending on the values at stake.

It is therefore reasonable to handle this idea in a similar way: When we make decisions in matters where some important value is at stake and when we suspect that a certain decision may result in serious damage to this value, and when a false negative would be a more substantial threat to the protection or promotion of this value than a false positive, then we should move our priorities from being biased towards avoiding false positives in the direction of avoiding false negatives.
It is important to note that it is not a matter of going from a system that is totally immune to false positives to one that is totally immune to false negatives. A system immune to false positives would not produce any statements about the world at all (only analytical statements would pass the test); while a system that is immune to false negatives would not be able to exclude anything other than pure contradictions. Everything else would be considered possible, and no possibility could ever be excluded from our considerations. What we need is a shift of focus from a bias against false positives in the direction of decreasing the risk of false negatives in situations where false negatives would have worse consequences than false positives. Just as with the importance of being in time, this should not affect the epistemic values inherent in science, that is, it should not affect which statements are to be included in the scientific corpus, only how scientific findings are to be used in society where other values are at stake. Just like with the previous idea, it is perfectly rational to adjust our criteria to fit our goals and it would in fact be irrational and unjustifiable not to do it.

Just as was the case with the importance of being in time, it was not possible to draw any conclusions form the standard formulations about when in fact it is more important to avoid false negatives than false positives. This question therefore has to be left to future work, or be left to be worked out in each particular case based on discussion between stakeholders regarding the values at stake.

Imagine for instance a case where a county considers whether to implant a new fish species in a lake. The fish species has recently become very popular with anglers and has created both jobs and tax revenues in another county where the fish occurs naturally. The lake where we plan to implant the fish is located in an area with a relatively high unemployment rate and no other exploitable resources. The ecosystem in the lake in question is different form the lake where the fish occurs naturally. An investigation performed by a consultancy firm has concluded that the environment is none the less suitable for this species. A nature conservation organisation has expressed worries about whether the species might be invasive and they got support from researchers at a nearby university who state that since this fish species has not been introduced in this kind of environment before, there is no positive evidence that it will be invasive, but that this case is in certain respects similar to other cases where implanted species have turned out to be invasive. The only way to confirm the suspicion and be able to say for certain that this particular fish species would be invasive in this particular environment. Is this a case where it is more important to avoid a false negative statement than a false positive? The answer obviously depends on which end result is least preferable. In this case we have indications that the species might be invasive but nothing that can be considered a scientifically sound proof. The question of which outcome is the least preferable, a devastated ecosystem or a foregone chance to create a flowering tourism industry in the area depends on too many unknown variables to be summarised in a general principle. It also includes the question of how different stakeholders value the different options. These are questions that cannot be answered by any reasonable formulation of the Precautionary Principle. The Precautionary Principle is not, and cannot be a tool for prioritizing between values. A reasonable formulation, like the one provided here, can however tell us which kind of situations we need to look out for. In this case situations where it is at least as important to avoid false negative statements as false positive statements.

\section{Summary and conclusions}

By analysing the most influential formulations of the Precautionary Principle I have identified four basic ideas behind the principle. All of them are ideas about which circumstances that justify extra precaution 
rather than which measures to take when extra precaution is called for. Each of these ideas is analysed separately, and the analysis shows that each one of them is independently sufficient to justify extra precaution. In fact, the four core ideas all describe cases where extra precaution is the only rational alternative.

The four items on the list provide sound justification for extra precaution beyond what would follow from standard decision methods such as cost-benefit analyses under any of the following circumstances:

* When we deal with important values that tend to be systematically downplayed by traditional decision methods - such as (but not necessarily exclusively) human health and the environment.

* When we suspect that the decision might lead to irreversible and severe consequences, and where the values at stake are also irreplaceable.

* When timing is at least as important as being right.

* When it is more important to avoid false negatives than false positives.

The conclusion is therefore that the Precautionary Principle is actually a list of circumstances where it is justified to take extra precaution beyond what traditional decision methods would recommend.

This means that it is not just the question of what measures to take when extra precaution is called for that goes unanswered in this formulation. It also fails to provide any objective standard for when the four circumstances pointed out by the core ideas, occur. In the first case, when human health or the environment is threatened, it can be seen as a given. In other cases such as when it is more important to avoid false positives than false negatives or when it is more important to be in time than being exactly right, it is not specified when that is. The principle says for instance that extra precaution is called for when it is more important to be in time than to be exactly right, but it does not tell us when it is more important to be in time than to be exactly right.

The reason why no objective criteria is specified in the core ideas is that none of the standard formulations make any specifications of that kind. This can be seen as a weakness in the principle but also as strength in that it provides room for discussion about the values at stake in each respective case. Either way, it could be perceived to view this rather stripped down formulation of the Precautionary Principle as fulfilling the aim stated in the introduction of a formulation of the Precautionary Principle that is "more useful in practice". I believe, however, that a principle that is clear within given boundaries is more useful than a principle that has no other wider boundaries but is helplessly fuzzy.

Having identified the core ideas behind the Precautionary Principle is also very helpful if we want to continue to develop the principle, though there is also another alternative, and that is to settle with defining the Precautionary Principle as tool for deciding under which general circumstances extra precaution is justified, and leave the remaining questions to be dealt with by other decision methods. I will here leave the question open for which path to take, though I lean towards the second alternative for two reasons. 1. (Referring to the lack of objective criteria for when the circumstances occur). This is basically a question of values and it seems more democratic to leave this to the democratic process rather than including it in a general principle masquerading as objective criteria. 2. (Referring to the lack of advice for which precautionary measures to take). There is a virtually infinite number of possible measures to take to decrease risk and which measure that is best for the job seems to depend on a number of variables that shift from case to case.

A bonus result of the investigation is that much of the common objections of the Precautionary Principle can be shown to be misdirected since they typically aim at what the Precautionary Principle supposedly tells us to do, for example to reverse the burden of proof, to demand proof of a negative, to ignore or downplay science, or to favour status quo.

\section{References}

Ambrus, M., 2012. The precautionary principle and a fair allocation of the burden of proof in international environmental law. Review of European Community \& International Environmental Law 21, 259-270.

Attfield, R., 1998. Environmental ethics and intergenerational equity. Inquiry 41, 207-422.

Barbier, E.B., 1994. Valuing environmental functions: tropical wetlands. Land Econ. 70, 155-173.

Beltrán, D.J., 2001. Preface. In: Herremoës, P., et al. (Eds.), Late Lessons From Early Warnings - The Precautionary Principle 1896-2000. Copenhagen: European Environment Agency, pp. 3-5.

Chan, K.M.A., Satterfield, T., Goldstein, J., 2012. Rethinking ecosystem services to better address and navigate cultural values. Ecol. Econ. 74, 8-18.

Chee, Y.E., 2004. An ecological perspective on the valuation of ecosystem services. Biol. Conserv. 120, 549-565

Commonwealth Consolidated Acts: Environment Protection and Biodiversity Conservation act 1999 - Sect 391. http://www.austlii.edu.au/cgi-bin/sinodisp/ au/legis/cth/consol_act/epabca1999588/s391.html, 2009 Accessed (2014.10.20).

Cooney R. From promise to practicalities: the precautionary principle in biodiversity conservation and sustainable use. In: Cooney R. Dickson B, editors. Biodiversity \& the Precautionary Principle. London: Earthscan; 2005. p. 3-17.

Cooney, R., Dickson, B. (Eds.), 2005. Biodiversity \& the Precautionary Principle. Earthscan, London.

Costanza, R., Folke, C., 1997. Valuing ecosystem services with efficiency, fairness and sustainability as goals. In: Daily, G.C. (Ed.), Nature's Services: Societal Dependence on Natural Ecosystems. Island Press, Washington, pp. 49-68.

Costanza, R., et al., 1997. The value of the world's ecosystem services and natural capital. Nature 387, 253-260.

Diamond, P.A., Hausman, J.A., 1994. Contingent valuation: is some number better than no number? J. Econ. Perspect. 8, 45-64.

Farman, J., 2001. Halocarbons, the ozone layer and the precautionary principle. In: Herremoës, P., et al. (Eds.), Late Lessons From Early Warnings - The Precautionary Principle 1896-2000. European Environment Agency, Copenhagen, pp. 76-83.

Garrod, G., Willis, K.G., 1999. Economic Valuation of the Environment. Edward Elgar Publishing, Cheltenham.

Gee, D., Greenberg, M., 2001. Asbestos - from magic to malevolent material. In: Herremoës, P., et al. (Eds.), Late Lessons From Early Warnings - The Precautionary Principle 1896-2000. Copenhagen, European Environment Agency, pp. 52-63.

Gignon, M., et al., 2013. The precautionary principle: is it safe. European Journal of Health Law 20, 261-270.

Gollier, C., Treich, N., 2003. Decision-making under scientific uncertainty - the economics of the precautionary principle. J. Risk Uncertain. 27, 77-103.

Graham, D., 2001a. A future for the precautionary principle? J. Risk Res. 4, 109-111.

Graham, D., 2001b. Decision-analytic refinements of the precautionary principle. J. Risk Res. 4, 127-141.

Grandjean, P., 2004. Implications of the precautionary principle for primary prevention and research. Annu. Rev. Public Health 25, 199-223.

Grandjean, P., et al., 2004. Implications of the precautionary principle in research and policy-making. Am. J. Ind. Med. 45, 482-485.

Herendeen, R.A., 1998. Monetary-costing environmental service: nothing is lost, something is gained. Ecol. Econ. 25, 29-30.

Hermele, K., 1995. Ekonomerna, tillväxten och miljön. Carlssons, Stockholm.

Herremoës, P., et al., 2001. Late Lessons From Early Warnings - The Precautionary Principle 1896-2000. European Environment Agency, Copenhagen.

Ibarreta, D., Swan, S.H., 2001. The DES story - long-term consequences of prenatal exposure. In: Herremoës, P., et al. (Eds.), Late Lessons From Early Warnings - The Precautionary Principle 1896-2000. European Environment Agency, Copenhagen, pp. 84-92.

Infante, P.F., 2001. Benzene - an historical perspective on the American and European occupational setting. In: Herremoës, P., et al. (Eds.), Late Lessons From Early Warnings - The Precautionary Principle 1896-2000. European Environment Agency, Copenhagen, pp. 38-51.

Koppe, J.G., Keys, J., 2001. PCBs and the precautionary principle. In: Herremoës, P., et al (Eds.), Late Lessons From Early Warnings - The Precautionary Principle 1896-2000. European Environment Agency, Copenhagen, pp. 64-75.

Lambert, B., 2001. Radiation - early warning; late effects. In: Herremoës, P., et al. (Eds.), Late lessons from early warnings - the precautionary principle 1896-2000. European Environment Agency, Copenhagen, pp. 31-37.

Lin, J.C., 2001. The precautionary principle - a rose by another name. IEEE Antennas and Propagation Magazine 43, 129-131.

Ludwig, D., 2000. Limitations of economic valuation of ecosystems. Ecosystems 3, 31-35.

Manson, N.A., 2002. Formulating the precautionary principle. Environ. Ethics 24, 263-274.

Manson, N.A., 2007. The concept of irreversibility: its use in the sustainable development and precautionary principle literatures. Electr. J. Sustain. Dev. 1, 3-15.

Mayer, B., Brown, P., Linder, M., 2002. Moving further upstream: from toxics reduction to the precautionary principle. Public Health Rep. 117, 574-586.

McGarvin, M., 2001. Fisheries - taking stock. In: Herremoës, P., et al. (Eds.), Late Lessons From Early Warnings - The Precautionary Principle 1896-2000. European Environment Agency, Copenhagen, pp. 17-30.

Melin, A., 2001. Judgements in Equilibrium? - An Ethical Analysis of Environmental Impact Assessment. Linköping University, Linköping.

Munthe, C., 1997. Etiska aspekter på jordbruk. Jordbruksverket, Jönköping.

Naidoo, R., Ricketts, T.H., 2006. Mapping the economic costs and benefits of conservation. PLoS Biol. 4 (11), 2153-2164, e360.

Neurath, O., 1973. Empiricism and Sociology. Reidel, Dordrecht. 
O'Neill, J., 2002. Socialist calculation and Environmental valuation: money, markets and ecology. Science \& Society 66, 137-151.

O'Riordan, T., Jordan, A., 1995. The precautionary principle in contemporary environmental politics. Environ. Values 4, 191-212.

Osimani, B., 2013. The precautionary principle in the pharmaceutical domain: a philosophical enquiry into probabilistic reasoning and risk aversion. Health, Risk \& Society $15,123-143$.

Owen, R.J., et al., 2009. Capturing old-growth values for use in forest decision-making. J. Environ. Manag. 43, 237-248.

Payne, J., et al., 1992. Behavioural decision research: a constructive processing perspective. Annu. Rev. Psychol. 43, 87-132.

Plottu, E., Plottu, B., 2007. The consept of total economic value of environment reconsideration within a hierarchical rationality. Ecol. Econ. 61, 52-61.

Purnhagen, K., 2014. The behavioural law and economics of the precautionary principle in the EU and its impact on internal market regulation. J. Consum. Policy 37, 453-464.

Raffensperger, C., Tickner, J.A., 1999. Protecting Public Health and the Environment: Implementing The Precautionary Principle. Island Press, Washington.

Randall, A., 1988. What mainstream economists have to say about the value of biodiversity. In: Wilson, E.O. (Ed.), Biodiversity. National Academy Press, Washington, pp. 217-223.

Raymond, C.M., et al., 2013. Ecosystem services and beyond: using multiple metaphors to understand human-environment relationships. Bioscience 63, 536-546.

Rio Declaration on Environment and Development 1992;§15.

Rolston III, H., 1988. Environmental Ethics - Duties to and Values in The Natural World. Temple University Press, Philadelphia.

Samples, K., Hollyer, P., 1990. Contingent valuation of wildlife resources in the presence of substitutes and complements. In: Johnson, R.L., Johnson, G.V. (Eds.), Economic Valuation of Natural Resources. Westview Press, Boulder, pp. 177-192.

Sandin, P., 1999. Dimensions of the precautionary principle. Hum. Ecol. Risk. Assess. 5, 889-907.

Sandin, P., 2004a. Introduction. In: Sandin, P. (Ed.), Better Safe than Sorry. Theses in Philosophy from the Royal Institute of Technology, Stockholm, pp. 1-8.
Sandin, P., 2004b. The precautionary principle and the concept of precaution. Environ. Values 13, 461-475

Sandin, P., 2006. A paradox out of context: Harris and Holm on the precautionary principle. Cambridge Quarterly of Health Care Ethics 15, 175-180.

Sandin, P., et al., 2002. Five charges against the precautionary principle. Journal of Risk Research 5, 287-290.

Söderbaum, P., 1987. Environmental management: a non-tradition al approach. J. Econ. Iss. 21, 139-165.

Söderbaum, P., 1994. Actors, ideology, markets. neoclassical and institutional perspectives on environmental policy. Ecol. Econ. 10, 47-60.

Steel, D., 2015. Philosophy and the Precautionary Principle - Science, Evidence, and Environmental Policy. Cambridge University Press, Cambridge.

Stijkel, A., Reijnders, L., 1999. Implementation of the precautionary principle in standards for the workplace. Occup. Environ. Med. 52, 304-312.

Sukhdev, P., 2010. Mainstreaming the Economics of Nature: A Synthesis of the Approach, Conclusions and Recommendations of TEEB. TEEB, Geneva.

Turner, D., Hartzell, L., 2004. The lack of clarity in the precautionary principle. Environ. Values 13, 449-460.

von Krauss, M.K., Herremoës, P., 2001. MTBE in petrol as a substitute for lead. In: Herremoës, P., et al. (Eds.), Late Lessons From Early Warnings - The Precautionary Principle 1896-2000. European Environment Agency, Copenhagen, pp. 110-125.

Walsh, J.R., 2004. Major infrastructure projects, biodiversity and the precautionary principle: the case of the Yacyretá dam and Iberá marshes. Review of European Community and International Environmental Law 13, 61-71.

Wandall, B., 2004. Values in science and risk assessment. Toxicol. Lett. 152, 265-272.

Whiteside, K.H., 2006. Precautionary Politics. MIT Press, Cambridge.

Wilson, M.A., Howarth, R.B., 2002. Discourse-based valuation of ecosystem services: establishing fair outcomes through group deliberation. Ecol. Econ. 41, 431-443.

Wingspread Conference on the Precautionary Principle. 1998.

World Commission on Environment and Development, 1987. Our Common Future. Oxford University Press, Oxford. 